\title{
A Comparative Study of Artificial Neural Network and Response Surface Methodology for Optimization of Friction Welding of Incoloy $800 \mathrm{H}$
}

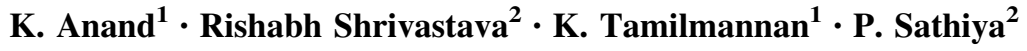

Received: 17 November 2014/Revised: 27 January 2015/Published online: 1 May 2015

(C) The Chinese Society for Metals and Springer-Verlag Berlin Heidelberg 2015

\begin{abstract}
This article deals with the optimization of process parameters for friction welding of Incoloy $800 \mathrm{H}$ rod and compares the results obtained by response surface methodology (RSM) and artificial neural network (ANN). The experiments were carried out on the basis of a five-level, four-variable central composite design. The output parameters were the tensile strength and burn-off length (BOL). They were considered as a function of four independent input variables, namely heating pressure (HP), heating time, upsetting pressure (UP), and upsetting time. The RSM results showed that the quadratic polynomial model depicted the interconnection between individual element and response. For optimizing the process parameters, ANN analysis was used, and the optimal configuration of the ANN model was found to be 4-9-2. For modeling aspect, a requisite trained multilayer perceptron neural network was rooted, and a quick propagation training algorithm was used to train ANN. The purpose of optimization was to decide the maximum tensile strength and minimum burn-off length of the welded joint which was done by varying the friction welding process variables. The order of importance of input parameters for friction welding of Incoloy $800 \mathrm{H}$ was HP $>\mathrm{UP}>\mathrm{N}>\mathrm{BOL}$. After predicting the model using RSM and ANN, a comparison was made for predicting the effectiveness of two methodologies. By analyzing the results, it was observed that as compared to RSM, ANN model was more specific.
\end{abstract}

KEY WORDS: Artificial neural network; Burn-off length; Response surface methodology; Tensile strength

\section{Introduction}

Incoloy $800 \mathrm{H}$ is a nickel-iron-chromium alloy with high rupture strength and good resistance to high-temperature corrosion. Incoloy $800 \mathrm{H}$ shows an excellent protection from oxidation and carburization at high temperature because of $\mathrm{Cr}_{2} \mathrm{O}_{3}$ scale formation [1]. Carbon content in

Available online at http://link.springer.com/journal/40195

P. Sathiya

psathiya@nitt.edu

1 School of Engineering and Technology, Indira Gandhi National Open University, New Delhi 110016, India

2 Department of Production Engineering, National Institute of Technology, Tiruchirappalli 620015, Tamilnadu, India
Incoloy $800 \mathrm{H}$ is more than the one in Incoloy $800 \mathrm{HT}$ and Incoloy 800. This extra carbon content controls the grain size, and it in turn optimizes the rupture properties. Due to its excellent property at high temperature, Incoloy $800 \mathrm{H}$ finds application in heat-exchanging equipments, chemicalprocessing units, pressure vessels, hot ducts, fuel cladding, and super-heaters and re-heaters in power plants [2, 3]. Heterogeneous metals are needed to be joined for various applications. In all these applications, usage of conventional process for welding is not feasible due to the development of low-melting intermetallics and its brittle nature [4]. As no melting occurs, the friction welding can be regarded as a forging technique. The friction welding is applied in the welding of various shaft and tubular parts in industries such as automotive, aircraft, farm equipment, and petroleum and natural gas. Melting temperature of base metal is higher than the temperature generated in friction 
welding. For making good-quality joint, the process parameters play a vital role [5]. To obtain desired result, a number of experiments are required for proper selection of input parameters, which are very tiresome and time taking. This problem can be overcome by a mathematical model which provides interconnection between various input and output variables. RSM and ANN techniques were used in this work for performing the above function. We are going for nonlinear analysis, and RSM and ANN gave very accurate result for that. RSM gave more accurate result as compared to other technique when the function was quadratic, whereas ANN had universal approximation capability, i.e., it could be used for approximating all type of nonlinear problems.

RSM was applied for optimizing response which was the function of some independent variable. Box and Wilson suggested a second-degree polynomial model for obtaining optimal response. This model was used because it was easy to assess and implement even when not much information was available about the process. Artificial neural network are computational methodologies used to estimate function that depends on large number of inputs inspired by biological neurons network. This model contains layer of simple computing nodes that work as nonlinear summing devices. Weighted connection line interconnects these nodes, and during a training process, the weights are adjusted as data and are presented to the network. Udaykumar et al. [6] used the friction welding for joining duplex stainless steel and analyzed the microstructure and mechanical properties of the weld. They concluded that the austenite was present in the ferrite matrix, and they also mentioned that the hardness of weld was more as compared to base metal. Elatharasan et al. [7] used RSM method for optimization of FSW AA 6061-T6 alloy. They took revolution per minute (RPM), transverse speed, and axial force as process parameters and tensile strength (TS) and yield strength (YS) as response. They concluded that with the increase in RPM and transverse speed, TS and YS increased at first and then decreased after achieving maximum value. Ghetiya et al. [8] used ANN for obtaining maximum tensile strength after FSW of aluminum (Al) alloy. The input parameters considered were shoulder diameter, tool RPM, and welding speed. Mourabet et al. [9] did a comparison between RSM and ANN method in predicting TS of FSW AA7039 Al alloy. They concluded that ANN was more specific as compared to RSM. Li et al. [10] investigated the electrochemical degradation of BPB dye with BDD anode under a range of major operating parameters. Nasr et al. [11] predicted the groundwater salinity (i.e., in terms of TDS) based on alkalinity (i.e., expressed by $\mathrm{pH}$ ) and proposed the ANN structure for that. Lakshminarayanan et al. [12] compared RSM and ANN method for predicting the tensile strength of friction-stir-welded AA7039 aluminum alloy joints. The process parameters used were welding speed, rotational speed, and axial force. The experiments were conducted based on three-factor, three-level, and central composite face-centered design with full replications technique, and the mathematical model was developed. The results obtained through response surface methodology were compared with those obtained through artificial neural networks. They concluded that ANN model was much more robust and accurate in estimating the values of the tensile strength as compared to response surface model. Betiku et al. [13] investigated the potential of shea butter oil (SBO) as feedstock for synthesis of biodiesel. Due to high free fatty acid (FFA) of SBO used, response surface methodology (RSM) was employed to model and optimize the pretreatment step, while its conversion to biodiesel was modeled and optimized using RSM and artificial neural network (ANN). Coefficient of determination and absolute average deviation were used by them for comparing the two methods. In this work, the friction welding of Incoloy 800 HT material was performed, and the responses considered were the tensile strength and burn-off length. The reason for choosing these two as responses instead of the yield strength or deformation was that Incoloy $800 \mathrm{HT}$ was used for high-temperature applications such as heat exchanger and super-heater. In these areas, mechanical loadings were not that much important, and so the main consideration was the ability of material to withstand high temperature. That is why we had concentrated more on the tensile strength and burn-off length instead of the yield strength or deformation.

\section{Experimental}

For neatness of the sample, at first, each surface was scrubbed with acetone. On the basis of machine capacity, the parameters for welding were chosen. Friction welding parameters used in this work were heating pressure (45-125 MPa), upsetting pressure (140-200 MPa), upsetting time (5-9 s), and heating time (4-8 s). The rotational speed was kept constant to $1500 \mathrm{rpm}$. A parameter was changed in each investigation from low to high level. The specimens were polished by $\mathrm{SiC}$ abrasive paper. The size of the grit used for polishing the specimen was in the range of 180-1200. Then, 3- $\mu \mathrm{m}$ diamond pastes were used for light polishing. For neatness, the sample was washed, cleansed by acetone, and after that it was allowed to dry. Electrolytic etching was performed with $10 \%$ oxalic acid at $9 \mathrm{~V}$ for a period of $30 \mathrm{~s}$ as per ASTM E3-11. Universal testing machine with capacity of 40 ton was used for evaluating the mechanical characteristics of the friction weld. Before testing the sample, the flash was machined from weld, and the size of base material used for testing 
was of gauge length $120 \mathrm{~mm}$ and diameter $9 \mathrm{~mm}$. For each welding experiment, three measurements were taken to calculate the average data.

CCD matrix was used for designing the experiment. It comprised of 30 sets of coded condition as shown in Figs. 1 and 2 [9]. It consisted of 24 designs, six center points, and eight star points. Center point was constructed by the welding parameters of average level (0), and star point was constructed by the welding parameters of highest $(+1)$ and lowest $(-1)$ level. With the help of 30 experimental runs, quadratic, continuous, and interactive effects of the friction welding parameters could be estimated. The experiment design matrix and output responses are presented in Table 1.

\section{Methodology}

\subsection{Response Surface Methodology}

Central composite design (CCD) helps in the efficient construction of second-order model. For assessing tuning parameters, CCD was built by additional axial and center points. Three-design-variable CCD is shown in Fig. 3. The design consisted of $2 \mathrm{~N}$ factorial points, $2 \mathrm{~N}$ axial points, and one central point as in Fig. 3. For the purpose of reducing the experiments, CCD was preferred over full factorial design. Time consumed for doing the experiment depended upon the number of design variable selected.

Design of experiment (DoE) was used for selecting the response which was to be assessed. Nearly every criterion was associated with mathematical modeling for achieving optimality in design. The mathematical model used was polynomial with indefinite structure, and so for each problem, the corresponding experiment was needed to be

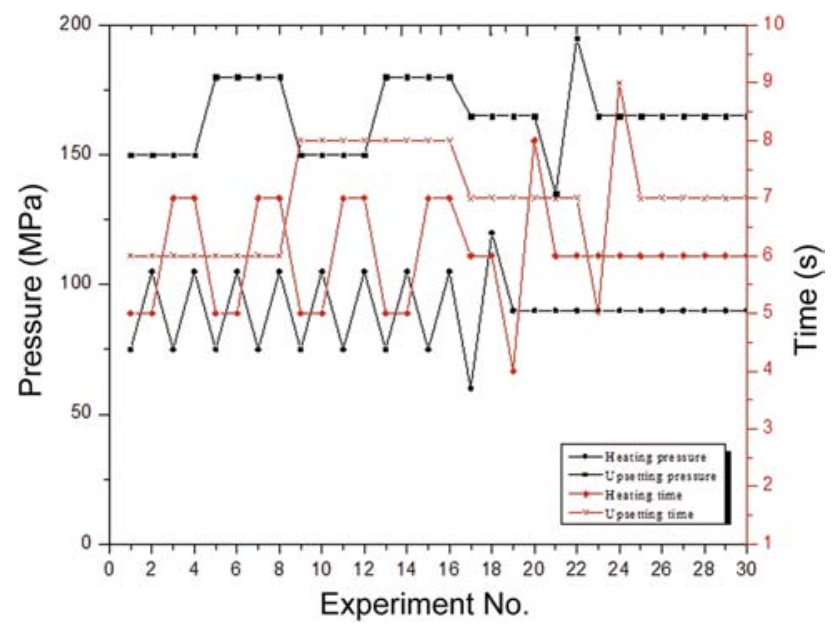

Fig. 1 Welding parameters used from experiment No. 1 to No. 30

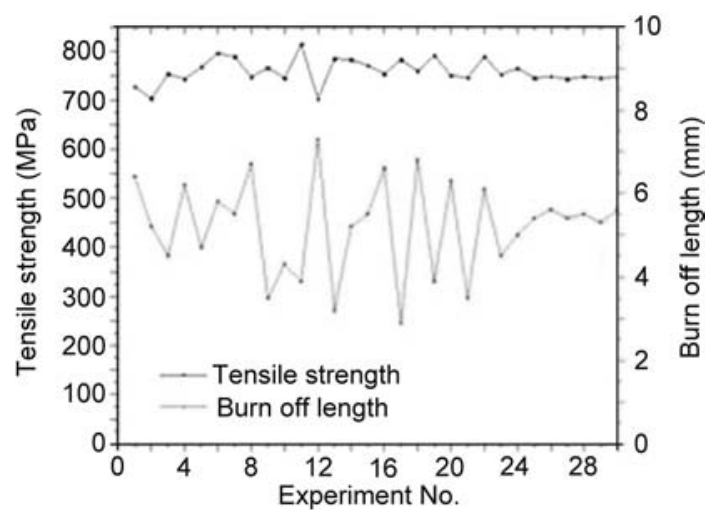

Fig. 2 Values of the tensile strength and burn-off length from experiment No. 1 to No. 30

designed. All the experimental inputs were entered, and using a single block process was continued. The standard column was arranged in an ascending order, and select type column was arranged in space-point-type configuration for the further requirements. After completion of all the sequential operations, the response pertaining to each and every experimental input was entered so as to analyze the result in a proper manner. This was to be carried out properly as all the further processes were based on the responses entered. Analysis of the responses was done individually. Through transform option, design expert provided a complete array of response conversions. At this point, it fitted the linear, two-factor interaction (2FI), quadratic, and cubic polynomials to the response. For producing analysis of variance, ANOVA tab was selected. Tables 2 and 3 show the ANOVA for the tensile strength and burn-off length.

Central composite design was adopted in RSM for optimizing process parameters using the given inputs obtained from the experiments that were carried out on the Incoloy $800 \mathrm{H}$ in working condition. Thus, the process was optimized, and the optimized value for the process was found out along with the maximization of the tensile strength and minimization of burn-off length.

\subsection{Artificial Neural Network}

Learning of the data involves proper settlements of the learning configurations involving the following adjustments: (1) selection of learning algorithm, (2) selection of connection type, (3) proper setting up of a learning parameters viz. learning rate, momentum and screen update rate, (4) selection of stopping criteria, and (5) in the final stage of learning algorithm, normalization of values between -1 and +1 .

Graphical variations of the responses on the basis of learning algorithms are shown in Fig. 4. The basic idea of 
Table 1 Experimental design matrix and output responses

\begin{tabular}{|c|c|c|c|c|c|c|}
\hline No. & $\begin{array}{l}\text { Heating pressure } \\
(\mathrm{MPa})\end{array}$ & $\begin{array}{l}\text { Heating time } \\
\text { (s) }\end{array}$ & $\begin{array}{l}\text { Upsetting pressure } \\
(\mathrm{MPa})\end{array}$ & $\begin{array}{l}\text { Upsetting time } \\
\text { (s) }\end{array}$ & $\begin{array}{l}\text { Tensile strength } \\
\text { (MPa) }\end{array}$ & $\begin{array}{l}\text { Burn-off length } \\
(\mathrm{mm})\end{array}$ \\
\hline 1 & 75 & 5 & 150 & 6 & 727.53 & 6.4 \\
\hline 2 & 105 & 5 & 150 & 6 & 703.78 & 5.2 \\
\hline 3 & 75 & 7 & 150 & 6 & 753.60 & 4.5 \\
\hline 4 & 105 & 7 & 150 & 6 & 743.49 & 6.2 \\
\hline 5 & 75 & 5 & 180 & 6 & 768.08 & 4.7 \\
\hline 6 & 105 & 5 & 180 & 6 & 796.08 & 5.8 \\
\hline 7 & 75 & 7 & 180 & 6 & 788.82 & 5.5 \\
\hline 8 & 105 & 7 & 180 & 6 & 748.20 & 6.7 \\
\hline 9 & 75 & 5 & 150 & 8 & 766.58 & 3.5 \\
\hline 10 & 105 & 5 & 150 & 8 & 746.10 & 4.3 \\
\hline 11 & 75 & 7 & 150 & 8 & 814.70 & 3.9 \\
\hline 12 & 105 & 7 & 150 & 8 & 703.14 & 7.3 \\
\hline 13 & 75 & 5 & 180 & 8 & 785.25 & 3.2 \\
\hline 14 & 105 & 5 & 180 & 8 & 782.44 & 5.2 \\
\hline 15 & 75 & 7 & 180 & 8 & 771.59 & 5.5 \\
\hline 16 & 105 & 7 & 180 & 8 & 754.15 & 6.6 \\
\hline 17 & 60 & 6 & 165 & 7 & 783.40 & 2.9 \\
\hline 18 & 120 & 6 & 165 & 7 & 759.52 & 6.8 \\
\hline 19 & 90 & 4 & 165 & 7 & 791.03 & 3.9 \\
\hline 20 & 90 & 8 & 165 & 7 & 750.84 & 6.3 \\
\hline 21 & 90 & 6 & 135 & 7 & 746.27 & 3.5 \\
\hline 22 & 90 & 6 & 195 & 7 & 789.38 & 6.1 \\
\hline 23 & 90 & 6 & 165 & 5 & 753.09 & 4.5 \\
\hline 24 & 90 & 6 & 165 & 9 & 765.55 & 5 \\
\hline 25 & 90 & 6 & 165 & 7 & 745.39 & 5.4 \\
\hline 26 & 90 & 6 & 165 & 7 & 748.4 & 5.6 \\
\hline 27 & 90 & 6 & 165 & 7 & 743.2 & 5.4 \\
\hline 28 & 90 & 6 & 165 & 7 & 748.6 & 5.5 \\
\hline 29 & 90 & 6 & 165 & 7 & 745.1 & 5.3 \\
\hline 30 & 90 & 6 & 165 & 7 & 747.7 & 5.6 \\
\hline
\end{tabular}

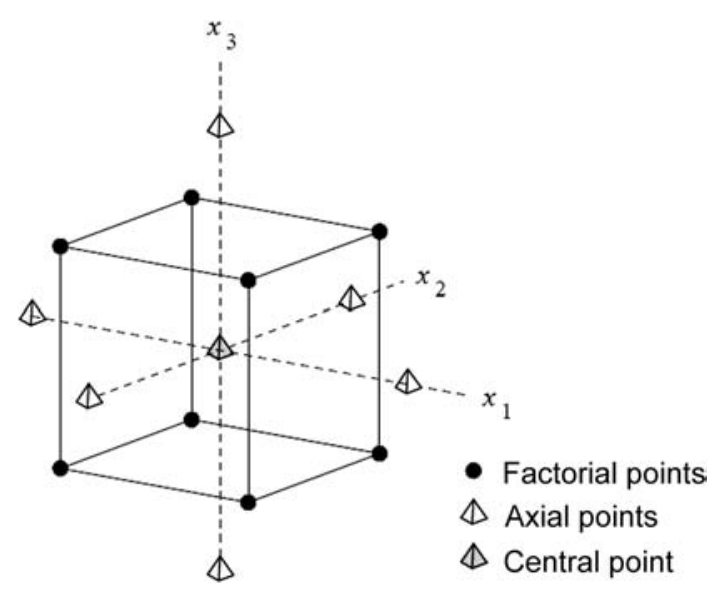

Fig. 3 Central composite design the ANN methodology was the optimization of the process parameters used in friction welding using the given inputs obtained from the experiments carried out on the Incoloy $800 \mathrm{H}$ in a working condition. Thus, the process was optimized, and the optimized value for the process was found out along with the maximization of the tensile strength and the minimization of the burn-off length.

\section{Results and Discussion}

\subsection{Response Surface Method}

RSM was employed to develop the method for optimizing and predicting the tensile strength and burn-off length in friction welding of Incoloy $800 \mathrm{H}$ under central composite 
Table 2 ANOVA for tensile strength (response 1)

\begin{tabular}{|c|c|c|c|c|c|c|}
\hline Source & S.S & DOF & M.S & $F$ Value & $p$ value & \\
\hline Model & $14,841.44$ & 14 & 1060.10 & 4.39 & 0.0037 & Significant \\
\hline A-heating pressure & 2532.38 & 1 & 2532.38 & 10.48 & 0.0055 & \\
\hline B-heating time & 256.96 & 1 & 256.96 & 1.06 & 0.3188 & \\
\hline C-upsetting pressure & 4317.75 & 1 & 4317.75 & 17.86 & 0.0007 & \\
\hline D-upsetting time & 592.92 & 1 & 592.92 & 2.45 & 0.1381 & \\
\hline $\mathrm{AB}$ & 1613.83 & 1 & 1613.83 & 6.68 & 0.0208 & \\
\hline $\mathrm{AC}$ & 1106.06 & 1 & 1106.06 & 4.58 & 0.0493 & \\
\hline $\mathrm{AD}$ & 699.73 & 1 & 699.73 & 2.89 & 0.1095 & \\
\hline $\mathrm{BC}$ & 1225.53 & 1 & 1225.53 & 5.07 & 0.0398 & \\
\hline $\mathrm{BD}$ & 355.61 & 1 & 355.61 & 1.47 & 0.2439 & \\
\hline $\mathrm{CD}$ & 754.46 & 1 & 754.46 & 3.12 & 0.0976 & \\
\hline $\mathrm{A}^{2}$ & 676.74 & 1 & 676.74 & 2.80 & 0.1150 & \\
\hline $\mathrm{B}^{2}$ & 641.45 & 1 & 641.45 & 2.65 & 0.1241 & \\
\hline$C^{2}$ & 451.77 & 1 & 451.77 & 1.87 & 0.1917 & \\
\hline $\mathrm{D}^{2}$ & 102.40 & 1 & 102.40 & 0.42 & 0.5250 & \\
\hline Residual & 3625.58 & 15 & 241.71 & & & \\
\hline Lack of fit & 3602.10 & 10 & 360.21 & 76.71 & $<0.0001$ & Significant \\
\hline Pure error & 23.48 & 5 & 4.70 & & & \\
\hline Cor total & $18,467.02$ & 29 & & & & \\
\hline
\end{tabular}

Table 3 ANOVA for burn-off length (response 2)

\begin{tabular}{|c|c|c|c|c|c|c|}
\hline Source & S.S & DOF & M.S & $F$ value & $p$ value & \\
\hline Model & 29.41 & 14 & 2.10 & 4.04 & 0.0055 & Significant \\
\hline A-heating pressure & 13.35 & 1 & 13.35 & 25.69 & 0.0001 & \\
\hline B-heating time & 6.72 & 1 & 6.72 & 12.93 & 0.0026 & \\
\hline C-upsetting pressure & 2.10 & 1 & 2.10 & 4.04 & 0.0627 & \\
\hline D-upsetting time & 0.84 & 1 & 0.84 & 1.62 & 0.2220 & \\
\hline $\mathrm{AB}$ & 1.38 & 1 & 1.38 & 2.66 & 0.1239 & \\
\hline $\mathrm{AC}$ & 0.031 & 1 & 0.031 & 0.059 & 0.8115 & \\
\hline $\mathrm{AD}$ & 1.27 & 1 & 1.27 & 2.44 & 0.1394 & \\
\hline $\mathrm{BC}$ & 0.53 & 1 & 0.53 & 1.01 & 0.3305 & \\
\hline $\mathrm{BD}$ & 2.48 & 1 & 2.48 & 4.77 & 0.0452 & \\
\hline $\mathrm{CD}$ & 0.076 & 1 & 0.076 & 0.15 & 0.7082 & \\
\hline$A^{2}$ & 0.21 & 1 & 0.21 & 0.39 & 0.5393 & \\
\hline $\mathrm{B}^{2}$ & 0.016 & 1 & 0.016 & 0.030 & 0.8641 & \\
\hline $\mathrm{C}^{2}$ & 0.27 & 1 & 0.27 & 0.52 & 0.4832 & \\
\hline $\mathrm{D}^{2}$ & 0.34 & 1 & 0.34 & 0.66 & 0.4307 & \\
\hline Residual & 7.79 & 15 & 0.52 & & & \\
\hline Lack of fit & 7.72 & 10 & 0.77 & 52.64 & 0.0002 & Significant \\
\hline Pure error & 0.073 & 5 & 0.015 & & & \\
\hline Cor total & 37.21 & 29 & & & & \\
\hline
\end{tabular}

design of experiment. The equation below explains the relationship of the four independent variables, i.e., HP, HT, UP, and UT and output variables, i.e., tensile strength (TS) and burn-off length (BOL) of welded joints. Heating pressure had maximum effect on the tensile strength because it was responsible for the amount of heat generated at the joining surfaces, i.e., if less heating pressure was applied, then adhesion would not be proper which would further decrease the tensile strength, and similarly if heating pressure was more, then sufficient adhesion could be 

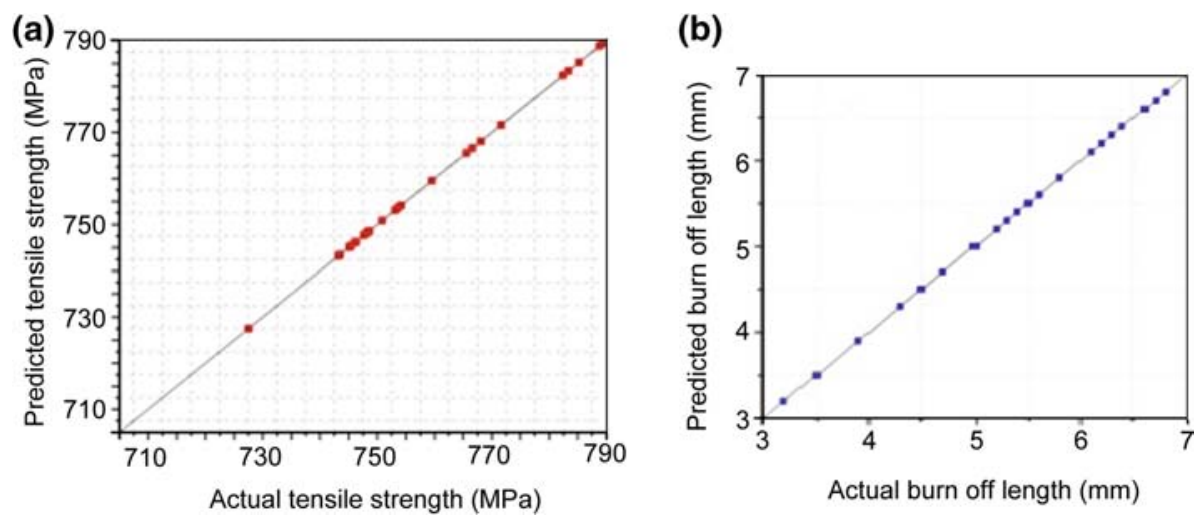

Fig. 4 Variation of responses on the basis of learning algorithm: a tensile strength, $\mathbf{b}$ burn-off length
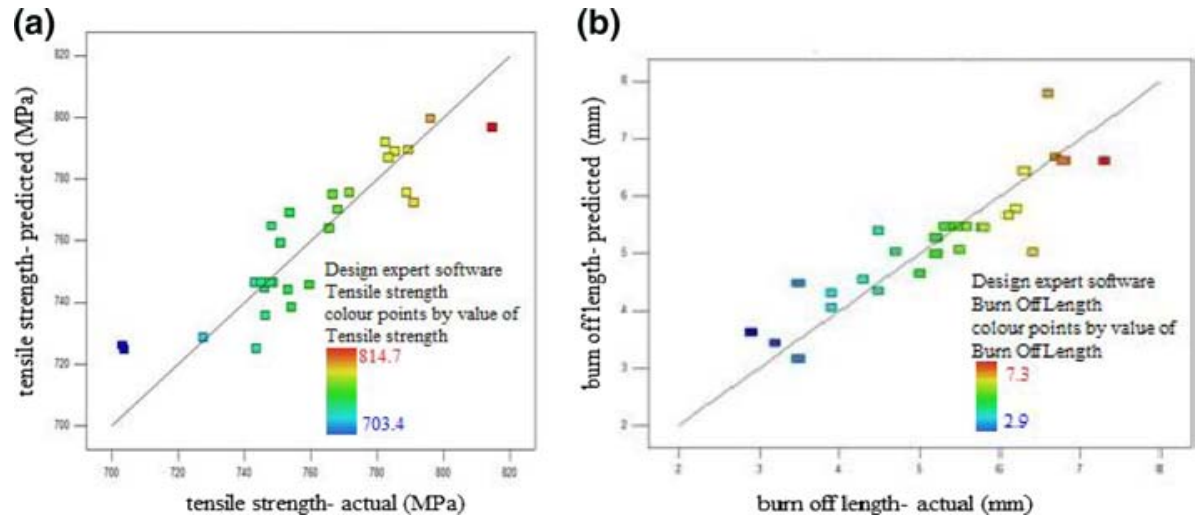

Fig. 5 Variation between the predicted and the actual values: a tensile strength, b burn-off length

obtained which would increase the tensile strength. From Fig. 5, we can conclude that predicted values of both the tensile strength and the burn-off length were in good agreement with observed values. By going through the contour plots (Figs. 6,7), the highest value of TS for the friction-welded Incoloy $800 \mathrm{H}$ was $788.975 \mathrm{MPa}$, and the minimum value of burn-off length was $3.442 \mathrm{~mm}$. From Fig. 7, it was clear that with the increase in upsetting time, tensile strength first decreased and after that it increased to peak value and afterward it again started declining, whereas with the rise in heating time, tensile strength went toward maxima and then it started to decline. This happened because sufficient heat could not be generated with shorter heating time, whereas long heating time resulted in the formation of intermetallics layer. High heating pressure and moderate upsetting pressure generated sufficient heat as a result of which strong adhesive bonding took place between faying surfaces. Upsetting time did not play major role in deciding burn-off length, whereas with an increase in heating pressure and heating time, burn-off length increased. The reason for the increase in burn-off length was the ease of material to be deformed because of the generation of high temperature. Upsetting pressure also affected burn-off length, and this occurred due to the forging action taking place in upsetting stage. The optimal values of various process parameters obtained by RSM method were heating pressure $75 \mathrm{MPa}$, heating time $5 \mathrm{~s}$, upsetting pressure $180 \mathrm{MPa}$, and upsetting time $8 \mathrm{~s}$. The equation obtained through design expert 9 for RSM method was given below for both tensile strength and burn-off length. The equation obtained was a quadratic one.

$$
\begin{aligned}
& \text { Burn-off length, } L=33.53333+0.16194 * \mathrm{HP} \\
& +5.69583 * \mathrm{HT}+0.042778 * \mathrm{UP} \\
& +3.43333 * \mathrm{UT}+0.019583 * \mathrm{HP} \\
& * \mathrm{HT}+(1.94444 E-004) * \mathrm{HP} * \mathrm{UP} \\
& +0.018750 * \mathrm{HP} * \mathrm{UT} \\
& +0.012083 * \mathrm{HT} * \mathrm{UP}+0.39375 \\
& * \mathrm{HT} * \mathrm{UT}+(4.58333 E-003) \\
& * \mathrm{UP} * \mathrm{UT}+(-3.84259 E-003) \\
& * \mathrm{UP} * \mathrm{UT}+(-4.39815 E-004) \\
& * \mathrm{HP} * \mathrm{HP}-0.023958 * \mathrm{HT} * \mathrm{HT} \\
& +(-4.39815 E-004) * \mathrm{UP} * \mathrm{UP} \\
& -0.1146 * \mathrm{UT} * \mathrm{UT} \text {. }
\end{aligned}
$$



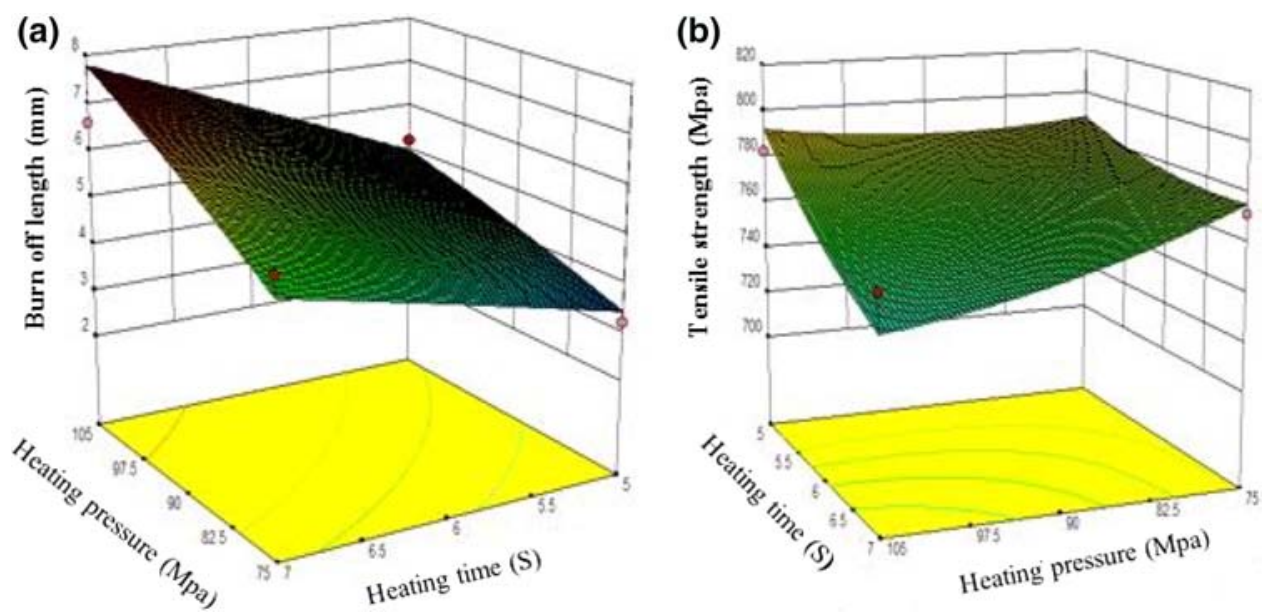

Fig. 6 Variation of response taking two parameters into account: a burn-off length, $\mathbf{b}$ tensile strength
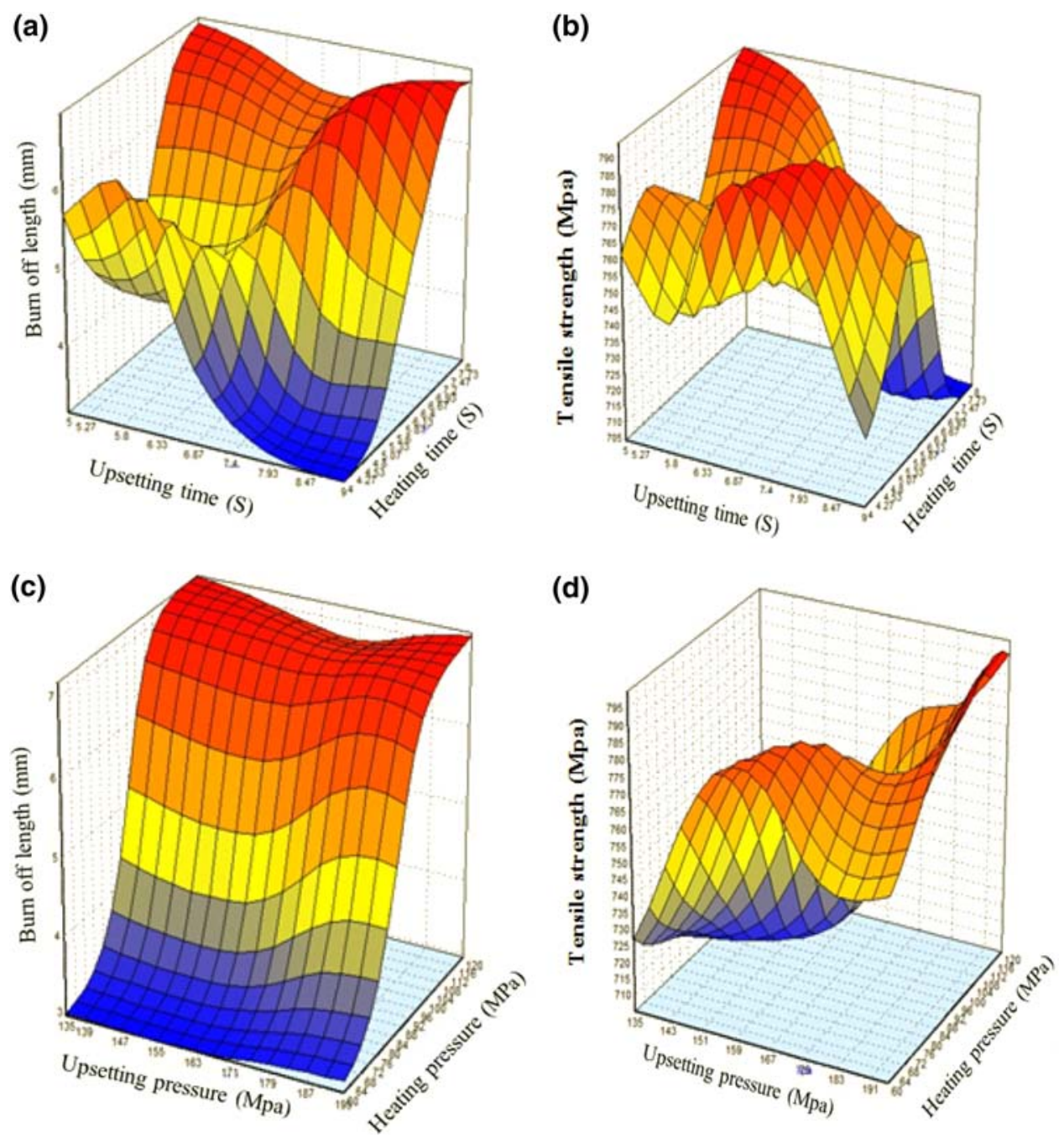

Fig. 7 Graphical variation of response with UT a, UP b, HT c, and HP d 


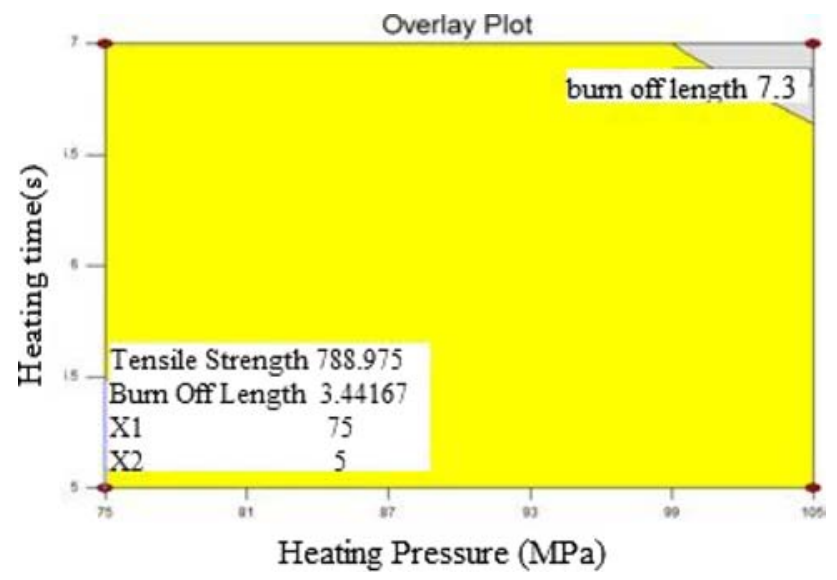

Fig. 8 Graphical solution E with number of neurons

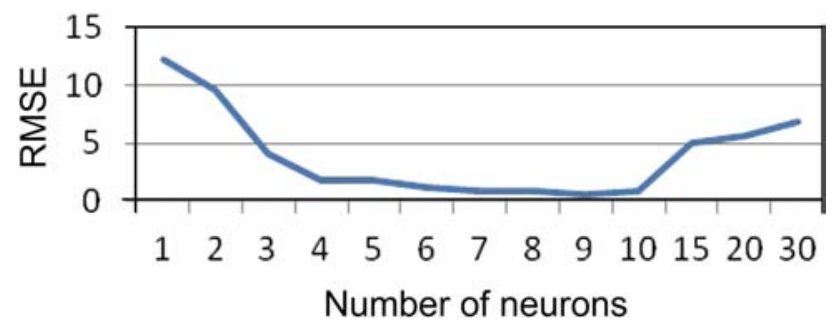

Fig. 9 Variation of RMSE with number of neurons

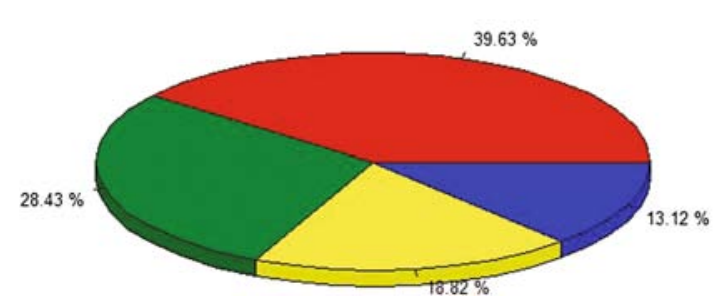

Fig. 10 Importance of parameters

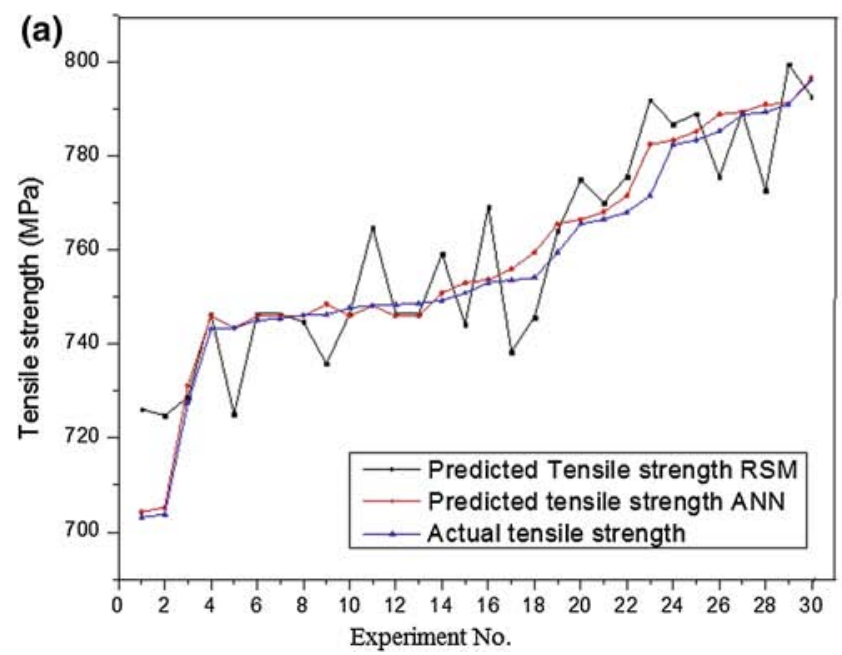

$$
\begin{aligned}
T S= & 189.05708-3.65239 * \mathrm{HP}+128.22667 * \mathrm{HT} \\
& -1.67864 * \mathrm{UP}+121.42042 * \mathrm{UT}-0.66954 * \mathrm{HP} * \mathrm{HT} \\
& +0.036953 * \mathrm{HP} * \mathrm{UP}-0.44088 * \mathrm{HP} * \mathrm{UT}-0.58346 \\
& * \mathrm{HT} * \mathrm{UP}-4.71438 * \mathrm{HT} * \mathrm{UT}-0.45779 * \mathrm{UP} * \mathrm{UT} \\
& +0.022076 * \mathrm{HT} * \mathrm{HT}+4.83594 * \mathrm{HT} * \mathrm{HT} \\
& +0.0118037 * \mathrm{UP} * \mathrm{UP}+1.93219 * \mathrm{UT} * \mathrm{UT} .
\end{aligned}
$$

The prediction of the optimized result was given through the numerical solution as in Table 3. Figure 5 shows the variation between predicted value and actual value, and it can be seen from Fig. 5 that the variation is within the limit. Figure 8 shows overlay plot for tensile strength and burn-off length. Overlay plot was used for finding the area (range of heating time and heating pressure) which gave the best possible value for each of the responses (i.e., the tensile strength and burn-off length). The value for the tensile strength was 788.975, and for burn-off length was 3.44167. Figure 6 shows the effect of heating pressure and heating time on the response, thus providing the optimal values of both the responses viz. the tensile strength and burn-off length.

\subsection{Artificial Neural Network}

The RMSE values were normalized and then graphically shown (Fig. 9). The value of $N$ was found which gave the lowest root-mean-square value. It turned out to 9 for the given case. Importance of parameters chart (Fig. 10) shows the weight age each input parameter had on the outputs namely, tensile strength. The optimal values of various process parameters obtained by ANN method were heating pressure $96 \mathrm{MPa}$, heating time $6.5 \mathrm{~s}$, upsetting pressure $162 \mathrm{MPa}$, and upsetting time $7.1 \mathrm{~s}$. The optimal values of

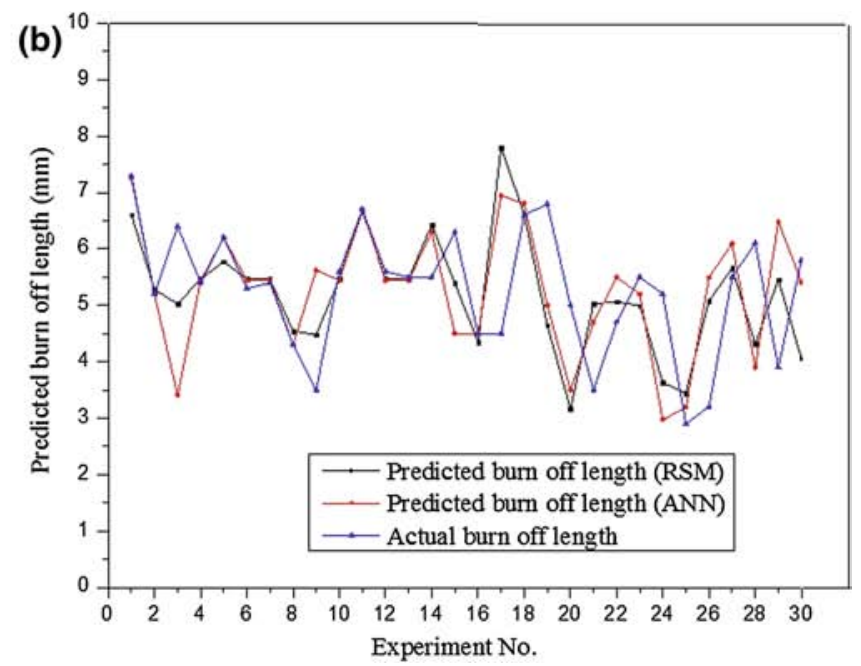

Fig. 11 Comparison of RSM and ANN and actual result: a tensile strength, b burn-off length 
Table 4 Numerical solution

\begin{tabular}{|c|c|c|c|c|c|c|c|c|c|}
\hline Factor & \multicolumn{2}{|l|}{ Name } & Level & \multicolumn{2}{|c|}{ Low level } & \multicolumn{2}{|c|}{ High level } & Std. Dev. & Coding \\
\hline A & \multicolumn{2}{|c|}{ Heating pressure } & 75 & \multicolumn{2}{|c|}{75} & \multicolumn{2}{|l|}{105} & 0 & Actual \\
\hline $\mathrm{B}$ & \multicolumn{2}{|c|}{ Heating time } & 5 & \multicolumn{2}{|c|}{5} & \multicolumn{2}{|l|}{7} & 0 & Actual \\
\hline $\mathrm{C}$ & \multicolumn{2}{|c|}{ Upsetting pressure } & 180 & \multicolumn{2}{|c|}{150} & 180 & & 0 & Actual \\
\hline $\mathrm{D}$ & \multicolumn{2}{|c|}{ Upsetting time } & 8 & \multicolumn{2}{|c|}{6} & 8 & & 0 & Actual \\
\hline Response & $\begin{array}{l}\text { Predicted } \\
\text { mean }\end{array}$ & $\begin{array}{l}\text { Predicted } \\
\text { median }\end{array}$ & Observed & Std. Dev. & SE Mean & $\begin{array}{l}\text { CI for } 95 \% \\
\text { CI low }\end{array}$ & $\begin{array}{l}\text { Mean } 95 \% \\
\text { CI high }\end{array}$ & $\begin{array}{l}99 \% \text { of } \\
95 \% \text { TI low }\end{array}$ & $\begin{array}{l}\text { Population } \\
\text { 95\% TI low }\end{array}$ \\
\hline Tensile strength & 788.975 & 788.975 & - & 15.5469 & 11.8741 & 763.665 & 814.284 & 710.6 & 867.349 \\
\hline Burn-off length & 3.44167 & 3.44167 & - & 0.720841 & 0.550551 & 2.26819 & 4.61514 & -0.19221 & 7.07554 \\
\hline
\end{tabular}

Table 5 Training and testing of observed and calculated data values

\begin{tabular}{|c|c|c|c|c|c|c|c|c|c|}
\hline $\mathrm{HP}(\mathrm{MPa})$ & HT (s) & UP (MPa) & UT (s) & Obs. TS (MPa) & Cal. TS (MPa) & Error TS & Obs. BOL (mm) & Cal. BOL (mm) & Error BOL \\
\hline \multicolumn{10}{|c|}{ Training data } \\
\hline 105 & 5 & 150 & 6 & 703.78 & 705.2276 & -1.4476 & 5.2 & 5.199837 & 0.000163 \\
\hline 75 & 7 & 150 & 6 & 753.6 & 753.70141 & -0.10141 & 4.5 & 4.4997583 & 0.000242 \\
\hline 105 & 7 & 150 & 6 & 743.49 & 743.44485 & 0.04515 & 6.2 & 6.1969736 & 0.003026 \\
\hline 75 & 5 & 180 & 6 & 768.08 & 768.09791 & -0.01791 & 4.7 & 4.7001832 & -0.00018 \\
\hline 75 & 7 & 180 & 6 & 788.82 & 788.89611 & -0.07611 & 5.5 & 5.4967858 & 0.003214 \\
\hline 105 & 7 & 180 & 6 & 748.2 & 748.14881 & 0.05119 & 6.7 & 6.7043847 & -0.00438 \\
\hline 75 & 5 & 150 & 8 & 766.58 & 766.53417 & 0.04583 & 3.5 & 3.4969953 & 0.003005 \\
\hline 105 & 5 & 150 & 8 & 746.1 & 746.03261 & 0.06739 & 4.3 & 4.2974884 & 0.002512 \\
\hline 105 & 7 & 150 & 8 & 703.14 & 704.27852 & -1.13852 & 7.3 & 7.2623413 & 0.037659 \\
\hline 75 & 5 & 180 & 8 & 785.25 & 785.22967 & 0.02033 & 3.2 & 3.1993729 & 0.000627 \\
\hline 105 & 5 & 180 & 8 & 782.44 & 782.47494 & -0.03494 & 5.2 & 5.2018448 & -0.00184 \\
\hline 75 & 7 & 180 & 8 & 771.59 & 771.57432 & 0.01568 & 5.5 & 5.4986131 & 0.001387 \\
\hline 60 & 6 & 165 & 7 & 783.4 & 783.37469 & 0.02531 & 2.9 & 2.972253 & -0.07225 \\
\hline 120 & 6 & 165 & 7 & 759.52 & 759.49861 & 0.02139 & 6.8 & 6.8055277 & -0.00553 \\
\hline 90 & 4 & 165 & 7 & 791.03 & 791.03473 & -0.00473 & 3.9 & 3.8972178 & 0.002782 \\
\hline 90 & 8 & 165 & 7 & 750.84 & 750.83974 & 0.00026 & 6.3 & 6.3025748 & -0.00257 \\
\hline 90 & 6 & 195 & 7 & 789.38 & 789.41401 & -0.03401 & 6.1 & 6.0990602 & 0.00094 \\
\hline 90 & 6 & 165 & 5 & 753.09 & 753.06673 & 0.02327 & 4.5 & 4.4996877 & 0.000312 \\
\hline 90 & 6 & 165 & 9 & 765.55 & 765.59917 & -0.04917 & 5 & 5.0002768 & -0.00028 \\
\hline 90 & 6 & 165 & 7 & 745.39 & 745.99812 & -0.60812 & 5.4 & 5.4405624 & -0.04056 \\
\hline 90 & 6 & 165 & 7 & 743.2 & 745.99812 & -2.79812 & 5.4 & 5.4405624 & -0.04056 \\
\hline 90 & 6 & 165 & 7 & 748.6 & 745.99812 & 2.60188 & 5.5 & 5.4405624 & 0.059438 \\
\hline 90 & 6 & 165 & 7 & 745.1 & 745.99812 & -0.89812 & 5.3 & 5.4405624 & -0.14056 \\
\hline 90 & 6 & 165 & 7 & 747.7 & 745.99812 & 1.70188 & 5.6 & 5.4405624 & 0.159438 \\
\hline \multicolumn{10}{|c|}{ Testing data } \\
\hline 75 & 5 & 150 & 6 & 727.53 & 731.1514 & -3.6214 & 6.4 & 3.4094221 & 2.990578 \\
\hline 105 & 5 & 180 & 6 & 796.08 & 791.12307 & 4.95693 & 5.8 & 6.4807053 & -0.68071 \\
\hline 75 & 7 & 150 & 8 & 814.7 & 815.39644 & -0.69644 & 3.9 & 5.4126274 & -1.51263 \\
\hline 105 & 7 & 180 & 8 & 754.15 & 756.03171 & -1.88171 & 6.6 & 6.9428238 & -0.34282 \\
\hline 90 & 6 & 135 & 7 & 746.27 & 748.47371 & -2.20371 & 3.5 & 5.6243483 & -2.12435 \\
\hline 90 & 6 & 165 & 7 & 748.4 & 745.99812 & 2.40188 & 5.6 & 5.4405624 & 0.159438 \\
\hline
\end{tabular}


Table 6 CCD matrix of four variables and the experimentally obtained tensile strength and burn-off length by RSM model predicted and ANN model predicted

\begin{tabular}{|c|c|c|c|c|c|c|c|c|c|}
\hline \multirow{2}{*}{$\begin{array}{l}\mathrm{HP} \\
(\mathrm{MPa})\end{array}$} & \multirow{2}{*}{$\begin{array}{l}\mathrm{HT} \\
\text { (s) }\end{array}$} & \multirow{2}{*}{$\begin{array}{l}\mathrm{UP} \\
(\mathrm{MPa})\end{array}$} & \multirow{2}{*}{$\begin{array}{l}\text { UT } \\
\text { (s) }\end{array}$} & \multirow{2}{*}{$\begin{array}{l}\text { Actual tensile } \\
\text { strength } \\
(\mathrm{MPa})\end{array}$} & \multirow{2}{*}{$\begin{array}{l}\text { Actual } \\
\text { burn-off } \\
\text { length }(\mathrm{mm})\end{array}$} & \multicolumn{2}{|c|}{ Predicted tensile strength (MPa) } & \multicolumn{2}{|c|}{ Predicted burn-off length (mm) } \\
\hline & & & & & & RSM & ANN & RSM & ANN \\
\hline 105 & 7 & 150 & 8 & 703.14 & 7.3 & 726.1391667 & 704.27852 & 6.6125 & 7.2623413 \\
\hline 105 & 5 & 150 & 6 & 703.78 & 5.2 & 724.8175 & 705.2276 & 5.279166667 & 5.199837 \\
\hline 75 & 5 & 150 & 6 & 727.53 & 6.4 & 728.6779167 & 731.1514 & 5.025 & 3.4094221 \\
\hline 90 & 6 & 165 & 7 & 743.2 & 5.4 & 746.3983333 & 745.99812 & 5.466666667 & 5.4405624 \\
\hline 105 & 7 & 150 & 6 & 743.49 & 6.2 & 725.1195833 & 743.44485 & 5.775 & 6.1969736 \\
\hline 90 & 6 & 165 & 7 & 745.1 & 5.3 & 746.3983333 & 745.99812 & 5.466666667 & 5.4405624 \\
\hline 90 & 6 & 165 & 7 & 745.39 & 5.4 & 746.3983333 & 745.99812 & 5.466666667 & 5.4405624 \\
\hline 105 & 5 & 150 & 8 & 746.1 & 4.3 & 744.6945833 & 746.03261 & 4.541666667 & 4.2974884 \\
\hline 90 & 6 & 135 & 7 & 746.27 & 3.5 & 735.80625 & 748.47371 & 4.479166667 & 5.6243483 \\
\hline 90 & 6 & 165 & 7 & 747.7 & 5.6 & 746.3983333 & 745.99812 & 5.466666667 & 5.4405624 \\
\hline 105 & 7 & 180 & 6 & 748.2 & 6.7 & 764.8041667 & 748.14881 & 6.679166667 & 6.7043847 \\
\hline 90 & 6 & 165 & 7 & 748.4 & 5.6 & 746.3983333 & 745.99812 & 5.466666667 & 5.4405624 \\
\hline 90 & 6 & 165 & 7 & 748.6 & 5.5 & 746.3983333 & 745.99812 & 5.466666667 & 5.4405624 \\
\hline 90 & 6 & 165 & 7 & 749.3 & 5.5 & 759.1979167 & 750.83974 & 6.429166667 & 6.3025748 \\
\hline 90 & 8 & 165 & 7 & 750.84 & 6.3 & 744.18625 & 753.06673 & 5.395833333 & 4.4996877 \\
\hline 90 & 6 & 165 & 5 & 753.09 & 4.5 & 769.1525 & 753.70141 & 4.345833333 & 4.4997583 \\
\hline 75 & 7 & 150 & 6 & 753.6 & 4.5 & 738.35625 & 756.03171 & 7.791666667 & 6.9428238 \\
\hline 105 & 7 & 180 & 8 & 754.15 & 6.6 & 745.7229167 & 759.49861 & 6.6125 & 6.8055277 \\
\hline 120 & 6 & 165 & 7 & 759.52 & 6.8 & 764.0679167 & 765.59917 & 4.645833333 & 5.0002768 \\
\hline 90 & 6 & 165 & 9 & 765.55 & 5 & 775.0075 & 766.53417 & 3.1625 & 3.4969953 \\
\hline 75 & 5 & 150 & 8 & 766.58 & 3.5 & 770.1125 & 768.09791 & 5.029166667 & 4.7001832 \\
\hline 75 & 5 & 180 & 6 & 768.08 & 4.7 & 775.5841667 & 771.57432 & 5.0625 & 5.4986131 \\
\hline 75 & 7 & 180 & 8 & 771.59 & 5.5 & 791.9191667 & 782.47494 & 4.995833333 & 5.2018448 \\
\hline 105 & 5 & 180 & 8 & 782.44 & 5.2 & 786.81125 & 783.37469 & 3.629166667 & 2.972253 \\
\hline 60 & 6 & 165 & 7 & 783.4 & 2.9 & 788.9745833 & 785.22967 & 3.441666667 & 3.1993729 \\
\hline 75 & 5 & 180 & 8 & 785.25 & 3.2 & 775.5795833 & 788.89611 & 5.075 & 5.4967858 \\
\hline 75 & 7 & 180 & 6 & 788.82 & 5.5 & 789.4579167 & 789.41401 & 5.6625 & 6.0990602 \\
\hline 90 & 6 & 195 & 7 & 789.38 & 6.1 & 772.28625 & 791.03473 & 4.3125 & 3.8972178 \\
\hline 90 & 4 & 165 & 7 & 791.03 & 3.9 & 799.5095833 & 791.12307 & 5.458333333 & 6.4807053 \\
\hline 105 & 5 & 180 & 6 & 796.08 & 5.8 & 796.6245833 & 815.39644 & 4.058333333 & 5.4126274 \\
\hline
\end{tabular}

the responses, i.e., tensile strength and burn-off length were 811.8774 MPa and $3.90442 \mathrm{~mm}$, respectively.

\subsection{Comparison of RSM and ANN Models}

In this work, a comparison of the capabilities of both the techniques (ANN and RSM) was made, and the estimation was examined. To accomplish this task, ANN and RSM techniques were used for predicting responses at experimental points (central composite design matrix). Then, the actual values were compared with anticipated values gathered from RSM and ANN. For comparison of ANN and RSM, root-mean-squared error (RMSE) and absolute average deviation (AAD) were used. The actual and predicted values for the central composite design matrix are presented in Fig. 11. The root-mean-squared error for design matrix by RSM and ANN for the tensile strength was 2.167 and 0.98031 , respectively, and for the case of burnoff length, it was 0.122 and 0.05054 , respectively. Figure 11 shows the comparison between actual and predicted values (RSM and ANN) of tensile strength and burn-off length.

\subsection{Confirmation Test}

By performing all the required operations, the optimal solution for that particular model was obtained. Further the process was confirmed for its optimal solutions with the help of the confirmation test. After finding the optimum settings based on the used models, the next step was to 
conform that they actually work. The confirmation experiment with triplicate set was conducted at the above specified optimum process conditions predicted by the model. In case of RSM models, the prediction interval narrowed down as the value of $\boldsymbol{N}$ (the number of confirmatory tests) increased.

The experiment was repeated in triplicate using the predicted optimal conditions determined by artificial neural network method. Predicted values and the values obtained by experiment were close enough; hence, the model was validated (Table 4). Thus, the model was useful to predict the optimal solution of the process (Tables 5, 6).

\section{Conclusions}

This work describes the use of central composite design matrix for conducting experiments on the friction welding of Incoloy $800 \mathrm{H}$. Two models were developed for predicting the responses viz. the tensile strength and burn-off length using RSM and ANN. First, RSM was applied for optimizing and predicting the responses. Then, the independent variables, namely HP, HT, UP, and UT, were fed as inputs to an ANN, while the output of the network was the tensile strength and burn-off length. Quick propagation algorithm was used for making different combination of input-output pattern which further trained a multilayer feed-forward network. At last for analyzing which method was more specific, the results obtained by RSM and ANN model were compared. Comparing prediction capabilities of both methodologies, we inferred that ANN gave solutions closer to the actual value as compared to RSM.

\section{References}

[1] A. Gutibrrez, J. de Damborenea, Oxid. Met. 47, 259 (1997)

[2] D.J. Kim, D.Y. Seo, J. Tsang, W.J. Yang, J.H. Lee, H. Saari, C.S. Seok, J. Mech. Sci. Technol. 26, 2023 (2012)

[3] H. Akhianin, M. Nezakat, J.A. Szpunar, Mater. Sci. Eng. A 614, 250 (2014)

[4] R. Paventhan, P.R. Lakshminarayanan, V. Balasubramanian, Trans. Nonferrous Met. Soc. China 21, 1480 (2011)

[5] S.T. Selvamani, K. Palanikumar, Measurement 53, 10 (2014)

[6] T. Udayakumar, K. Raja, A. Tanksale Abhijit, P. Sathiya, J. Manuf. Process. 15, 558 (2013)

[7] G. Elatharasan, V.S. Senthil Kumar, Procedia Eng. 64, 1227 (2013)

[8] N.D. Ghetiya, K.M. Patel, Procedia Technol. 14, 274 (2014)

[9] M. Mourabet, A. El Rhilassi, M. Bennani-Ziatni, A. Taitai, Univ. J. Appl. Math. 2, 84 (2014)

[10] W. Li, B. Li, W.C. Ding, J.Y. Wu, C.Y. Zhang, D.G. Fu, Diamond Relat. Mater. 50, 1 (2014)

[11] M. Nasr, H.F. Zahran, Egyptian J. Aquat. Res. 40, 111 (2014)

[12] A.K. Lakshminarayanan, V. Balasubramanian, Trans. Nonferrous Met. Soc. China 19, 9 (2009)

[13] E. Betiku, S.S. Okunsolawo, S.O. Ajala, O.S. Odedele, Renew. Energy 76, 408 (2015) 